drain searce talent from existing institutions is neces. sarily harder to deal with, if only because so much is bound to depend on estimates of how studies in molecular biology are likely to be stimulated by the creation of an international laboratory. Professor $\mathrm{V}$ Weisskopf (page 317) is able to claim that the growth of CERN has not been accompanied by a decline of high-energy physics elsewhere in Europe, and what he has to say is powerful reinforcement for the case in favour of the European laboratory. At the same time, however, it is only possible to guess at what would have happened to high-energy physics in Europe if CERN had not been built. Most probably, the thirteen mem. ber nations would have been egged on by competition to spend more, in aggregate, on this branch of physics, but would not have had such good value for money. And in this spirit, of course, the possibility that a European laboratory for molecular biology may drain away people from national laboratories--unrealistic though it may be-is almost irrelevant. What matters is that the people concerned should remain in circulation as innovators and as teachers. If that could be assured, the EMBO laboratory would be at worst a more economical way of doing business than the present system in which funds for the support of research in molecular biology are dispersed throughout the universities of Europe. In reality, there is probably a good deal in the claim of the EMBO council that a European laboratory would be a means by which contributing governments could gain markedly from quite small extra investments. In the long run, it would even be reasonable for them to expect that a successful EMBO laboratory would restrain the strictly national demand for an expanding budget.

All this, however, is hair-splitting of a kind. The truth is that the sums of money necessary for the funding of the EMBO laboratory, large though they may seem in comparison with the scale on which biological laboratories are habitually financed, are an exceedingly small part of what Europe as a whole chooses to spend on research of all kinds. Even if the EMBO venture should turn out to be a sheer waste of money-and all the evidence runs the other way-no great damage would have been done. In the eircumstances it will bo a great misfortune if the governments whose representatives are now trudging back from Geneva make too much of the issues of principle involved, and neglect the wider opportunities which the EMBO proposals offer. And these, in the long run, are plain enough. Sooner or later it will bo necessary to organize a great deal of European science on a co-operative basis. The sooner it is possible to set about the building of common institutions, the sooner Europeans will begin to profit from their common geography.

In that sense, EMBO and its laboratory are splendid opportunities for experiment.

\section{No Academic Spending Spree}

Tre University Grants Cornmittee has now published details of the allocations of recurrent grants to uni- versities in Great Britain over the next five years. The figures, which were sent to universities at the end of last year, are published in the UGC Annual Survey for the academic year 1966-67 (HMSO, 3s. 3d.), together with the memorandum which the UGC sent the universities to explain "the strategic attitude" which the UGC has had to adopt in order to make a division of the resources. Sir John Wolfenden is cheerful about the reception the memorandum received from the universities - at least, he said in presenting the report, there had been "no major explosion from the uni. versities" so far. The grants themselves confirm that the growth of universities is likely to move more slowly in the next five years than it has done in the last five. "Plain living and high thinking" was Sir John's recipe for the next quinquennium.

$\begin{array}{|cc|}\text { RECURRENT GRANTS FOR BRITISH UNTVERSITIES } \\ & \mathfrak{E} \text { (million) } \\ 1967-68 & 150 \cdot 79 \\ 1968-69 & 152 \cdot 85 \\ 1969-70 & 158 \cdot 57 \\ 1970-71 & 164 \cdot 82 \\ 1971-72 & 171 \cdot 10 \\ \text { (From 1968-69 onwards, the figures make no provision } \\ \text { for equipment for teaching and research, which will be } \\ \text { dealt with by separate grants.) }\end{array}$

The memorandum lays emphasis on the need to expand undergraduate numbers, in particular in the arts and social sciences. Sir John defends this decision by pointing out that, in 1964, the actual numbers of science students in the first-year sixth forms of British schools declined. Despite this, the UGC has provided for a slight increase in the numbers of science students at universities. But social science and the arts, where the pressure on university places is greatest, must be allowed to expand the fastest. The UGC has not fixed limits on the number of postgraduates which universities can provide for, but the grants awarded do make ccrtain assumptions about the proportion of undergraduates to postgraduates. As the report puts it, "It is, of course, open to any university to admit more than the number of students indicated in its separate allocation letter, if by internal economies, increased 'productivity' or any other means it thinks it can rightly do so".

The UGC has set in train a survey of the reasons why students entering universities fail to finish the course -the "drop-out" or wastage rate. At present in Britain, the wastage rate is running at about 14 per cent, but there is considerable variation both between departments and between universities. Suspicion has sometimes been voiced that some universities admit more students than they can possibly handle, and use the first year to weed them out. The survey, Sir John said, would try to sort out whether there was any truth in suggestions of this sort, and would try to make somo estimate of the reasons for wastage. Vicechancellors, he added, tended to be difficult about publishing this kind of information, so that discussion would be necded before it was finally decided what form the published survey should take.

In making the allocations to universities, the principal eriterion is the number of students in any uni- 
versity. This year, for the first time, the UGC has also taken into account unit costs, and staff : student ratios. Veterinary students come out as the most expensive, with a unit cost of $£ 1,136$, and social scientists are the cheapest at $£ 255$. The staff : student ratio is most favourable in veterinary science, at $1: 4 \cdot 6$, and least favourable in education, at $1: 12 \cdot 5$. Physical science, the report says, has a unit cost of $£ 376$ and staff : student ratio of $1: 11 \cdot 3$, but biological sciences are more expensive, with unit costs of $£ 518$ and staff : student ratios of $1: 8 \cdot 7$.

\section{Superannuated Dons}

AN alternative arrangement to the Federated Superannuation System for Universities receives consideration in a recent working party report, published by the Department of Education and Science. Headed by Sir George Maddex, the party represented a number of associations and committees and the government departments concerned. The alternative scheme which the committee considered is the terminal salary scheme.

The existing FSSU system is based on policies of assurance so that benefits reflect the actual amounts received as salary during an individual's career. This has led, the report maintains, to inadequate pensions. According to the alternative arrangement, a scheme would be adopted under which pension benefits would be directly related to the teacher's salary at retirement, thus giving weight to economic conditions at that particular time. The rates of benefit would be guaranteed, but the contributions would be fixed on a provisional basis. Because of a variety of reservations from members, however, the working party has been unable to make a clear recommendation in favour of either system.

The report includes an examination of the basic differences between terminal salary and insurance policy schemes, and it also considers the implications of tax and the National Insurance graduated pension scheme; the report compares them by working out the benefits in a number of typical cases. On a salary of $\mathfrak{E 2 , 0 0 0}$ a year, for example, assuming a contribution of 5 per cent, the net charge borne by a teacher according to the terminal salary scheme would be $£ 6718 s .4$., whereas according to the existing scheme

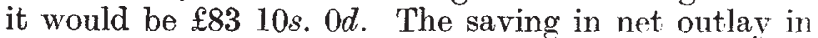
this case is 0.75 per cent of salary.

Figures of future FSSU benefits which are expressed as a percentage of benefits under a terminal salary scheme show that most teachers entering university service for the first time would do better with FSSU; the figures are, however, based on assumptions, certain of which, the report maintains, are of questionable validity. The working party agreed, however, that, if an alternative to the present system is required, the terminal salary scheme is the best that is possible in existing conditions.

\section{Marriage of Convenience}

THE announcement that the British Motor Corporation and Leyland Motors are to merge provides Britain with a motor company of international size. It is also a company with several built-in handicaps, the most serious of which may turn out to be the way in which its factories are scattered about the countryside.
Although this alone is likely to be a limitation on the amount of rationalization that is possible, Sir Donald Stokes, by common agreement the dominant force in the new company, will have plenty of room left for manoeuvre. His principal limitation in the short term is likely to be a shortage of funds, and the $£ 25$ million dowry with which the Industrial Reorganization Corporation blessed the union will come in very useful indeed.

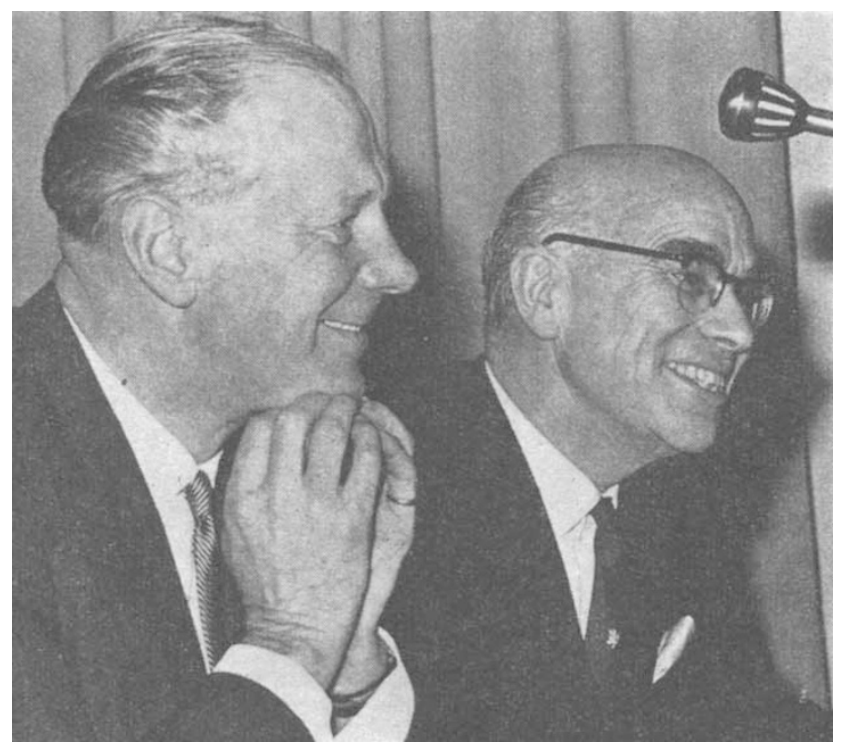

Sir George Harriman (left) and Sir Donald Stokes.

For this reason, it is fortunate that the early decisions Sir Donald, and his Chairman Sir George Harriman, will have to make will involve saving rather than spending money. It is almost certain that BMC's extensive range of cars will be reduced quite rapidly, by the disappearance of the Daimler name and the phasing out of several other models, perhaps including the 1800 . It has been said that the ranges of cars marketed by the two companies are complementary, but this is little more than the traditional incantation which is always murmured when two companies merge. In this case it is simply untrue-there is direct competition both in the sports car and saloon car ranges (the Austin 1300 and the Triumph 1300, for example) and since BMC took over Daimler there is also some overlap in commercial vehicles and coaches. So there is little doubt that some models will have to go; others will have to be introduced to challenge Ford's dominance of the middle of the range. Considerable economies are possible in dealerships and in export organization, and the intervention of Leyland makes it seem more likely that $\mathrm{BMC}$ will at last take advantage of the economies of scale which have been within its grasp since the formation of the Nuffield organization in 1952 .

In research, neither company has anything to match the $\& 1$ million research laboratory which Ford has built. In Leyland, research continues to be done by the individual companies, with Leyland itself perhaps doing the lion's share. It has, for example, built a gas turbine truck, and has pooled its knowledge with Rover, which has also done a good deal of work on gas turbine propulsion. The twin problems of pollution 